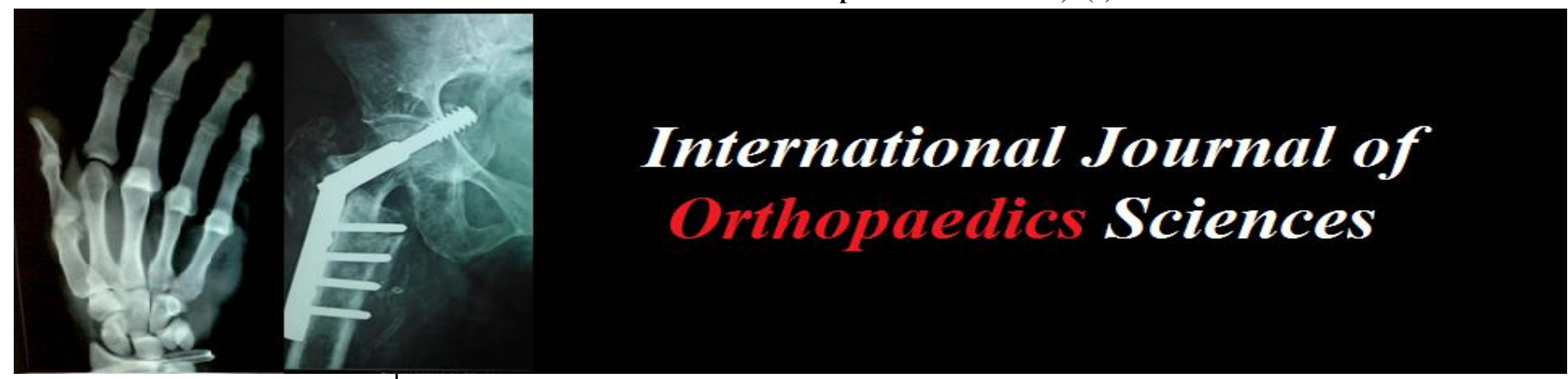

E-ISSN: 2395-1958

P-ISSN: 2706-6630

IJOS 2020; 6(1): 174-177

(C) 2020 IJOS

www.orthopaper.com

Received: 01-11-2019

Accepted: 05-12-2019

Dr. Piyush Wadhawan

Senior Resident, Department of

Orthopedics, Himalayan

Institute of medical sciences,

Swami Rama Himalayan

University, Dehradun,

Uttarakhand, India

Dr. Atul Agrawal

Professor, Department of

Orthopedics, Himalayan

Institute of medical sciences,

Swami Rama Himalayan

University, Dehradun,

Uttarakhand, India

Dr. Digvijay Agarwal

Assistant Professor, Department

of Orthopedics, Himalayan

Institute of medical sciences,

Swami Rama Himalayan

University, Dehradun,

Uttarakhand, India
Corresponding Author: Dr. Atul Agrawal Professor, Department of Orthopedics, Himalayan Institute of medical sciences, Swami Rama Himalayan University, Dehradun,

Uttarakhand, India

\section{Radiological evaluation of cementing quality in femoral stem arthroplasty, by free hand versus gun technique}

\author{
Dr. Piyush Wadhawan, Dr. Atul Agrawal and Dr. Digvijay Agarwal
}

DOI: https://doi.org/10.22271/ortho.2020.v6.i1d.1856

\begin{abstract}
Background: The objective of the study was evaluate radiologically the cementing quality of femoral stem in replacement of hip by free hand versus gun technique of cementing, using grading system of Barrack's and to find out intra observer agreement and inter observer agreement of grades for femoral stem cementation in hip replacement.

Methods: In the present experimental randomized study, 50 cases of hip arthroplasty were evaluated for cementing quality of femoral stem by free hand versus gun technique of cementing. Standard anterioposterior radiographs of hip with thigh was taken in 15 degree internal rotation and lateral view was taken in shoot through lateral projections. The radiographic evaluation of same radiographs was done at post op day one and after 6 weeks. All the subjects included in the study were subjected to comparison of cementing quality of femoral stem by using Barrack's cement grading system. The statistical analysis was done by using SPSS version 24.0; SPSS Inc. Chicago, Illinois, USA. Interpretation and analysis of obtained results was carried out by descriptive method and data presented as summary statistics. The Kappa coefficient was calculated by statistical analysis, which assessed the agreement among tests with categorical variables.

Results: The most frequent gradings were grade A in the hip replacements done by Gun technique and grade $\mathrm{B}$ in the cases done by Hand technique. We verified the Kappa coefficient for intra observer agreement ( 0.40 to 0.52$)$, which represented modest to moderate strength of agreement and Kappa coefficient for inter observer agreement ( 0.45 to 0.55$)$ which reported modest to moderate strength of agreement.

Conclusion: We conclude that the Gun technique of cementing is superior to the hand cementing technique. Simple radiographic evaluation is not suitable for the assessment of cementation quality, which support previous studies recommendation not to use radiographic grading systems alone as a marker for defining the longevity of the arthroplasty.
\end{abstract}

Keywords: hip arthroplasty, bone cement, barrack's grading, radiography, femoral stem

\section{Introduction}

Aseptic loosening is the number one cause of failure of cemented hip prosthesis. This failure rate is directly proportional to the quality of cementation of the femoral stem ${ }^{[1]}$. The occurrence of aseptic loosening is reduced by the modern joint replacement techniques. The use of superior cementing techniques are accountable for good cementing and longivity in hip arthroplasty ${ }^{[2]}$. The advantages of an ideal cementing are that they allow more filling of the medullary canal in substantial way and decrease in laminations, in the cement mantle ${ }^{[3]}$. With the employment of second generation cementing techniqus we are able to enhance cementbone interface strength and are also able to generate superior intrusion pressure of cement into the medulary canal ${ }^{[4]}$.

The radiological evaluation of postoperative radiographs is the most important tool to assess quality of cementation in hip arthroplasty and also frequently used on follow-up examinations ${ }^{[5]}$. The radiological appearance of a good cementing technique, such as the shape, thickness and reliability of the cement mantle as well as prosthesis alignment, are important factors predicting the permanence of cemented femoral implants ${ }^{[6]}$. Barrack et al. ${ }^{[7]}$ in 1992 published a method of grading of femoral cementing quality. It consists of criterias to specially determine the cementation quality of femoral component done by Cement gun technique and hand technique. It is proposed that this grading would help in recognizing stems with a threat 
of loosening. We aimed to evaluate radiologically the cementing quality of femoral stem in hip arthroplasty by free hand versus gun technique of cementing and to assess the reproducibility of this technique, so that it may be used more widely as criteria to define the longevity of cemented femoral prosthesis.

\section{Methods}

In the present experimental randomized study, 50 cases of hip arthroplasty were evaluated for cementing quality of femoral stem by free hand versus gun technique of cementing. The randomization was done by asking each patient to randomly pick a card from a box containing 25 cards each, with name A and with name B. Card A was allocated free hand cementing technique assigned as group A and Card B was allocated gun cementing technique assigned as group B. Once the card was taken out from the box that card was discarded.

Surgical approach to hip joint was anterior or posterior depending upon surgeons choice and method for femoral canal preparation was kept same for both groups with cement Palacos ${ }^{\circledR}$ MV (Heraeus). The OT temperature was kept at 18 degree Celcius standard.

\section{Cementing technique \\ Hand technique}

In this technique, the broaching the femoral canal was done without additional bone preparation. The canal was irrigated and suctioned before the digital application of cement. A poly etheyl plug was used as a cement restrictor. It helps in pressurization of cement in the medullary canal. It was introduced at proper depth in the medulary canal. The mixed and firmed cement was rolled into a roll and filled into the femoral canal using two finger of hand. No further movement of prosthesis or the bone was done after the placing of prosthesis into the femoral canal till the set time of cement was complete.

\section{Gun technique}

In the gun technique after broaching the femoral canal no additional bone preparation was done. The irrigated and suctioned of canal was done for removal of soft tissue debris. A poly etheyl plug was used as a cement restrictor. It helps in pressurization of cement in the medullary canal. It was introduced at proper depth in the medulary canal. A cement gun was used for introduction of doughy cement in a retrograde fashion. No further movement of prosthesis or the bone was done after the placing of prosthesis into the femoral canal till the set time of cement was complete.

The post-operative radiographs was taken on 11x14 film from a distance of 3 feet with zero \% magnification using allengers DR 800 MA machine. Standard anterio-posterior radiographs of hip with thigh was taken in 15 degree internal rotation and lateral view was taken in shoot through lateral projections. The radiographic evaluation of same radiographs was done at post op day one and after 6 weeks. All the subjects included in the study were subjected to comparison of cementing quality of femoral stem by using Barrack's ${ }^{[7]}$ cement grading system. (Table 1) The three observers (one senior consultant, one junior consultant, one post graduate resident) well versed with this grading method were asked to evaluate the AP and lateral radiograph of every hip. The radiographic films were coded and identities of patients were covered. The observers was asked to evaluate the same radiographs on 2 separate occasions-Post operative day one and after 6 weeks. On second evaluation of radiographs the arrangement and the code was changed. The observer was permitted to eliminate any film, which they feel not to be of appropriate quality. To relate the observer's responses we measured the Coefficient of Kappa with version 9.0 of the SAS/STAT® software. The interpretation of achieved results was carried out by illustrative method and data presented as summary statistics. The Kappa coefficient was calculated by statistical analysis, which evaluated the agreement among tests with categorical variables. The strength of agreement for the Kappa coefficient into six categories was divided by the Landis and Koch ${ }^{[8]}$. (Table 2)

Table 1: Barrack's ${ }^{[7]}$ Grading Method of Cementing

\begin{tabular}{|c|c|}
\hline Grades & Characteristics of radiographs \\
\hline A & The medullary canal fills entirely, no radiolucent Lines between bone and cement known as white-out. \\
\hline B & "The Fifty percent of the cement-bone interface cover up by radiolucent line." \\
\hline C & "Among Fifty percent and Ninety nine percent of the cement-bone interface covered by radiolucent lines." \\
\hline D & $100 \%$ of the cement-bone interface covered by radiolucent lines \\
\hline
\end{tabular}

Table 2: Categories of strength of agreement for the kappa coefficient ${ }^{[8]}$

\begin{tabular}{|c|c|}
\hline Kappa Coefficient & Strength of agreement \\
\hline Below zero & Poor \\
\hline $0-0.2$ & Negligible \\
\hline $0.21-0.4$ & Modest \\
\hline $0.41-0.6$ & Moderate \\
\hline $0.61-0.8$ & Substantial \\
\hline $0.81-1$ & Almost perfect \\
\hline
\end{tabular}

\section{Results}

The overall distribution of grades of the cementation quality in the antero-posterior and lateral $\mathrm{x}$-rays films by Hand \& Gun Technique shown in Table-3. On post-operative day 1 analysis, the maximum number of grade $\mathrm{A}$ score to gun technique was given by observer two (18 cases) \& to hand technique was given by observer two ( 8 cases). On 6 week analysis of radiographs the maximum number of grade A score to gun technique was given by observer one \& two (19 cases) \& to hand technique was given by observer three ( 7 cases). There was a much higher percentage of grade A given to the cases with gun technique in this study, averaging $80 \%$ of the reviewed radiographs. (Figure-1) Our study support the fact that the cement gun allows overall filling of canal and decreases the voids in the cement mantle. We verified the Kappa coefficient for intra observer agreement $(0.40$ to 0.52$)$ which indicates modest to moderate strength of agreement and Kappa coefficient for inter observer agreement ( 0.45 to $0.55)$ representing modest to moderate strength of agreement. (Table-4) 
Table 3: Grading of the cementation quality in the antero posterior and lateral radiographs by hand \& gun technique

\begin{tabular}{|c|c|c|c|c|c|c|c|}
\hline & & \multirow{2}{*}{ Technique } & \multicolumn{4}{|c|}{ Cementation Grades } & \multirow[t]{2}{*}{ Total } \\
\hline & & & $\mathbf{A}$ & B & $\mathbf{C}$ & D & \\
\hline \multirow{4}{*}{ Observer1 } & \multirow{2}{*}{ POD-1 } & Hand & 08 & 09 & 05 & 03 & 25 \\
\hline & & Gun & 17 & 07 & 0 & 01 & 25 \\
\hline & \multirow{2}{*}{ At 6 Weeks } & Hand & 06 & 11 & 07 & 01 & 25 \\
\hline & & Gun & 19 & 04 & 02 & 0 & 25 \\
\hline \multirow{4}{*}{ Observer2 } & \multirow{2}{*}{ POD-1 } & Hand & 17 & 06 & 02 & 0 & 25 \\
\hline & & Gun & 18 & 04 & 02 & 01 & 25 \\
\hline & \multirow{2}{*}{ At 6 Weeks } & Hand & 06 & 11 & 06 & 02 & 25 \\
\hline & & Gun & 19 & 04 & 02 & 0 & 25 \\
\hline \multirow{4}{*}{ Observer3 } & \multirow{2}{*}{ POD-1 } & Hand & 09 & 09 & 06 & 01 & 25 \\
\hline & & Gun & 17 & 06 & 02 & 0 & 25 \\
\hline & \multirow{2}{*}{ At 6 Weeks } & Hand & 07 & 13 & 04 & 01 & 25 \\
\hline & & Gun & 18 & 05 & 02 & 0 & 25 \\
\hline
\end{tabular}

Table 4: intra observer agreement of the cementation quality grading

\begin{tabular}{|c|c|}
\hline Observers & Kappa Coefficient \\
\hline Observer 1 & 0.404 \\
\hline Observer 2 & 0.528 \\
\hline Observer 3 & 0.458 \\
\hline
\end{tabular}

Table 5: inter observer agreement of the cementation quality grading

\begin{tabular}{|c|c|}
\hline Readings & Kappa coefficient \\
\hline Reading1 & 0.550 \\
\hline Reading 2 & 0.490 \\
\hline
\end{tabular}

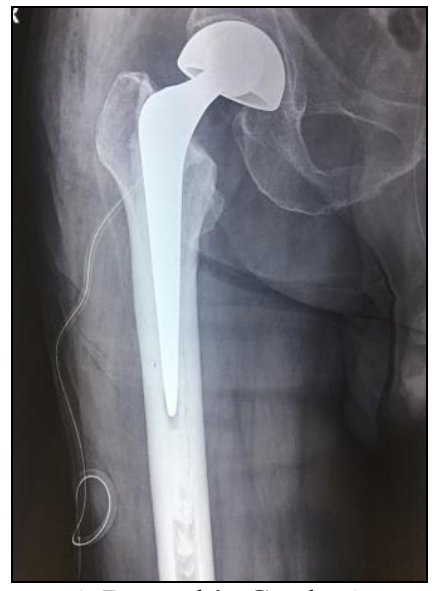

A Barrack's Grade-A

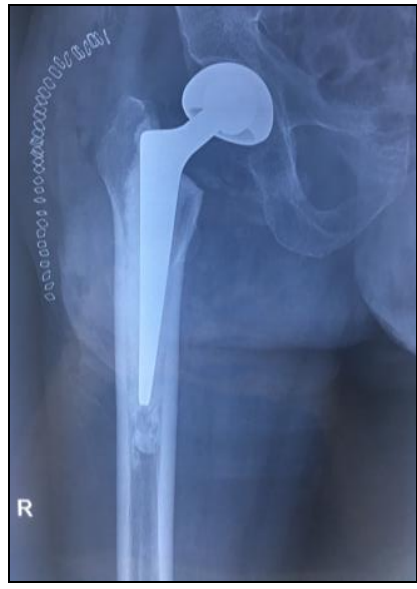

C Barrack’s Grade-B

g 1(A, B, C, D): The post-operative Standard Anterioposterior Lateral projection radiograph of hip with thigh of cemented hip arthroplasty done by Gun technique.

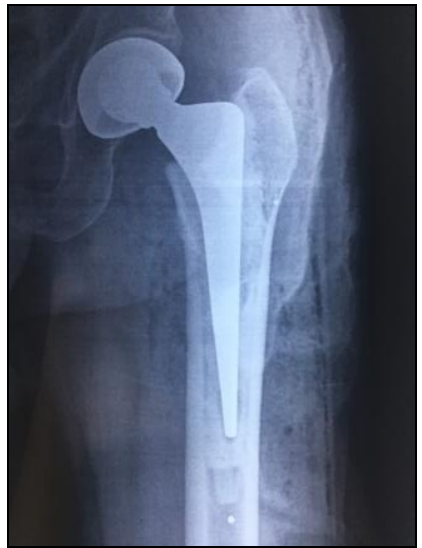

A Barrack's Grade-B

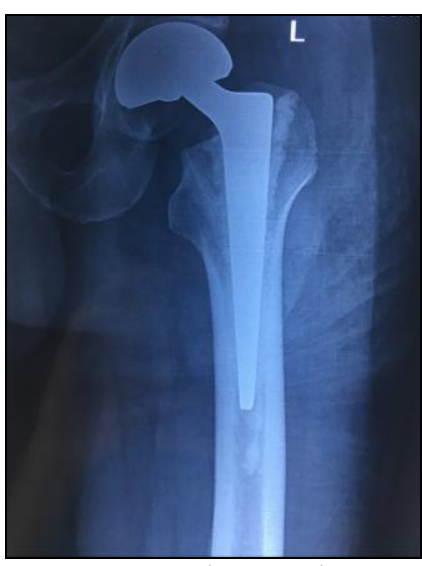

C Barrack's Grade-C

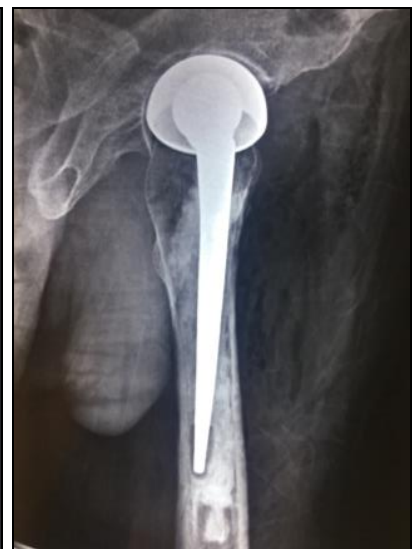

B Barrack’s Grade-B

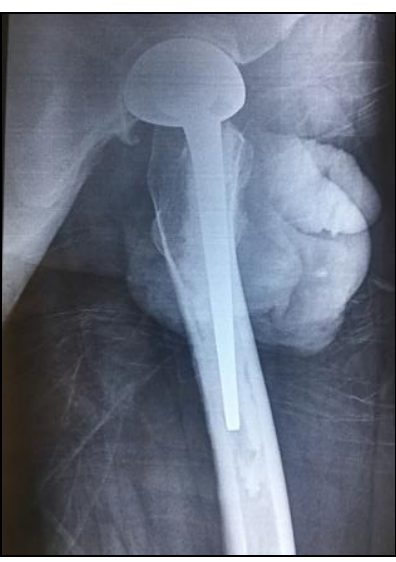

D Barrack’s Grade-C

Fig 2(A, B, C, D): The post-operative Standard Anterioposterior Lateral projection radiograph of hip with thigh of cemented hip arthroplasty done by Hand technique.

\section{Discussion}

A male preponderance was observed in this study. In the present study, $33(66 \%)$ were males and 17 (34\%) were females. Findings were coherent with the observational study conducted by Nath et al. ${ }^{[9]}$. Similar findings were seen in Indian Society of Hip and Knee Surgeons joint registry [10] where total number of 3604 Total hip replacement were documented. These comprised $2162(60 \%)$ male cases and $1442(40 \%)$ female cases, which emphasizes the fact that mostly males are the affected victim as they are most actively involved in outdoor physical activities and work.

It was found that maximum number of patients belonged to the age group 60-80 years. Harvey et al. In 1998 also reported that most of patient belongs to same age group with mean age of 76 years ${ }^{[5]}$. While Trumn et al. Reported a mean age of 62 years ${ }^{[11]}$. This is due to the fact that most of people in this age group suffer from osteoporosis hence prone to fracture neck femur or proximal femur pathology for which they required hip replacement surgeries for maintaining an active lifestyle.

In current study, it was found that that $41(82 \%)$ patients had indication of surgery as fracture neck of femur and $9(18 \%)$ patients had indication of surgery as avascular necrosis of femoral head and there was no patients with primary osteoarthritis. In the Indian Society of Hip and Knee Surgeons joint registry ${ }^{[10]}$ avascular necrosis of the hip was the indication for total hip replacement in $49 \%$ patients, with primary osteoarthritis in $10 \%$ patients and Fracture neck of femur in $7 \%$. In 1995 Siopack et al. ${ }^{[12]}$ reviewed the total hip replacement surgeries in the United States. 
They found severe osteoarthritis was the indication for total hip replacement in $70 \%$ patients. This difference in disease epidemiology could be explained by the fact that this is a completely different disease demography compared with Caucasian population where primary osteoarthritis of the hip is predominant. It also reveals the preponderance of Fracture neck of femur, hip avascular necrosis in the Indian subcontinent the etiology of which is likely to be osteoporosis, widespread steroid and alcohol abuse.

Our result also indicates that the system demonstrate poor credibility, with moderate intra and inter observer agreement. These findings are consonant with existing studies (Table 6), who in various cases noticed a level of agreement that was even less than anticipated inadvertently. We also propose that due to qualitative rather than quantitative nature of grades of Barrack's [7] system, there has been wide variation in interobserver agreement upon cementing quality. This has been explained by multiple studies upon inter observer agreement after Barrack's grading. We suggest that there is a need for better grading criteria with quantitative analysis (may be MRI/CT based) so that the post-operative cementing quality and prognostication for aseptic loosening could be done in a more standard manner which would be universally accepted to most of the surgeons.

While in current study the kappa coefficient of intraobserver agreement and interobserver agreement is modest to moderate strength of agreement, we can still suggest that the results would be acceptable over a wide range of observers, at least in our study.

Due to the simplicity of Barrack's grading system. It may visible to be the most reliable one. In our study we also got this to be so. This grading system has been utilized to assess the cementation quality after the establishment of secondgeneration techniques and has been used to determine aseptic loosening (Barrack et al. 1992).

Table 6: Comparison among the Data of Different Studies on the Reproducibility of the Barrack Grading System

\begin{tabular}{|c|c|c|c|c|}
\hline Author & Number of arthroplasties & Number of observers & Intra K (strength of agreement) & Inter K (strength of agreement) \\
\hline McCaskie et al. ${ }^{[13]}$ & 30 & 6 & 0.07 to 0.63 (negligible to substantial) & 0.48 to 0.18 (poor to negligible) \\
\hline Kelly et al. ${ }^{[16]}$ & 60 & 2 & 0.49 to 0.53 (moderate) & 0.38 to 0.43 (negligible to moderate \\
\hline Harvey et al..$^{[5]}$ & 100 & 3 & not tested & 0.56 to 0.73 (moderate to substantial \\
\hline Ilizaliturri et al. ${ }^{[14]}$ & 22 & 3 & not tested & 0.19 to 0.27 (negligible to modest) \\
\hline This study & 50 & 3 & 0.40 to 0.52 (modest to moderate) & 0.45 to 0.55 (modest to moderate) \\
\hline
\end{tabular}

The limitation of our study are that sample size is not very big, we have not able to include functional results due to the longer follow up needed \& variation in the interpretation of Barrack's Grading system.

\section{Conclusion}

The Gun technique of cementing is superior to the hand cementing technique. The cement gun decreases the laminations and the voids in the cement mantle and helps in more absolute filling of the medullary canal. Overall, intraobserver agreement aggrement and interobserver agreement was ranged between modest to moderate with levels related to or less than those predictable by chance. Our results suggest that such systems (Barrack's grading) cannot offer reliable data from centers in diverse parts of the world, with a variety of levels of surgeon assessing radiographs at different time intervals. The scoring systems may be more consistent, when applied by those who made them, but when they are used at other centers and by diverse level of surgeon, our study shows that they are less dependable.

\section{References}

1. Malik MH, Fisher N, Gray J, Wroblewski BM, Kay PR. Prediction of Charnley femoral stem aseptic loosening by early post-operative radiological features. Int. Orthop. 2005; 29(5):268-71.

2. Mulroy RD Jr, Harris WH. The effect of improved cementing techniques on component loosening in total hip replacement. An 11-year radiographic review. J Bone Joint Surg Br. 1990; 72(5):757-60.

3. Petruskevicius J. Optimizing the cementation of femoral component in hip arthroplasty. 2010; 11:7-12.

4. Oh I, Carlson C, Tomford W, Harris W. Improved fixation of the femoral component after total hip replacement using a methacrylate intramedullary plug. J Bone Joint Surg [Am]. 1978; 60:608-613.

5. Harvey EJ, Tanzer M, Bobyn JD. Femoral cement grading in total hip arthroplasty. J Arthroplasty. 1998;
13(4):396-401.

6. Kelly AJ, Lee MB, Wong NS, Smith EJ, Learmonth ID. Poor reproducibility in radiographic grading of femoral cementing technique in total hip arthroplasty. J Arthroplasty. 1996; 11(5):525-8.

7. Barrack RL, Mulroy RD Jr, Harris WH. Improved cementing techniques and femoral component loosening in young patients with hip arthroplasty. A 12-year radiographic review. J Bone Joint Surg Br. 1992; 74(3):385-9.

8. Landis JR, Koch GG. The measurement of observer agreement for categorical data. Biometrics. 1977; 33(1):159-74.

9. Nath R, Gupta AK, Chakravarty U, Nath R. Primary cemented total hip arthroplasty: 10 years follow-up. Indian J Orthop. 2010; 44(3):283-8.

10. Pachore JA, Vaidya SV, Thakkar CJ, Bhalodia HKP, Wakankar HM. ISHKS joint registry: A preliminary report. Indian J Orthop. 2013; 47(5):505-9.

11. Trumm BN, Callaghan JJ, George CA, Liu SS, Goetz DD, Johnston RC. Minimum 20-year follow-up results of revision total hip arthroplasty with improved cementing technique. J Arthroplasty. 2014; 29(1):236-41.

12. Siopack JS, Jergesen HE. Total hip arthroplasty. West J Med. 1995; 162(3):243-9.

13. McCaskie AW, Brown AR, Thompson JR, Gregg PJ. Radiological evaluation of the interfaces after cemented total hip replacement. Interobserver and intraobserver agreement. J Bone Joint Surg Br. 1996; 78(2):191-4.

14. Ilizaliturri VM Jr, Bobadilla G, Espinosa R, Garin DE, Chaidez PA, Valero FS et al. Plug migration and cement mantle assessment in total hip replacement. Int Orthop. 2004; 28(1):11-5. 